\title{
Candida albicans isolated from denture-related stomatitis in elderly patients: Antifungal susceptibility and production of virulence attributes
}

\author{
Lourimar Viana Nascimento Franco de Sousa ${ }^{1}$, Carlos Davi de Oliveira Maia ${ }^{1}$, \\ Isadora Sousa Carvalho ${ }^{1}$, Juliano Meireles Prata ${ }^{1}$, Larissa Carla Rodrigues Arcanjo ${ }^{1}$, \\ Marina de Figueiredo Vieira ${ }^{1}$, Matheus Batista Martins ${ }^{1}$, Thais Silveira Pereira ${ }^{1}$, \\ Lucieri Olegário Pereira Souza ${ }^{2}$, Anna Clara Milesi Galdino ${ }^{2,3}$, Marta Helena Branquinha ${ }^{2}$ (D), \\ Heliara Maria Spina Canela ${ }^{4}$ and André Luis Souza Santos ${ }^{2,3}$

\begin{abstract}
${ }^{1}$ Universidade Vale do Rio Doce (UNIVALE), Campus II, Governador Valadares, Minas Gerais, Brazil, ${ }^{2}$ Laboratório de Estudos Avançados de Microrganismos Emergentes e Resistentes (LEAMER), Departamento de Microbiologia Geral, Instituto de Microbiologia Paulo de Góes (IMPG), Universidade Federal do Rio de Janeiro (UFRJ), Rio de Janeiro, Brazil, ${ }^{3}$ Programa de Pós-Graduação em Bioquímica, Instituto de Química, Universidade Federal do Rio de Janeiro (UFRJ), Rio de Janeiro, Brazil, and

${ }^{4}$ Faculdades IESGO, Formosa, Goiás, Brazil

*Corresponding authors: Emails: lourimar.sousa@univale.br and andre@micro.ufrj.br
\end{abstract}

(Received 06 June 2020; Revised 20 August 2020; Accepted 07 September 2020)

\begin{abstract}
Denture-related stomatitis caused by Candida spp. affects elderly individuals using partial/total prosthesis, provoking several discomforts including burning sensation and altered taste. Herein, we have studied 52 denture-wearing individuals ( $>60$ years-old), attended at the dentistry clinic of UNIVALE, aiming to isolate Candida spp. directly from the stomatitis lesions and to evaluate their potential to produce virulence attributes. A low prevalence of denture-related stomatitis was reported in these patients $(4 / 52 ; 7.7 \%)$. Candida albicans was isolated in the 4 selected patients, with the ability to form biofilm over a polystyrene surface and to produce aspartic protease, esterase and hemolysin. However, neither phospholipase nor caseinase activities were detected. Planktonic-growing yeasts were susceptible to amphotericin B and caspofungin, while the susceptibility to azoles (fluconazol, itraconazole and voriconazole) varied depending on either the isolate or antifungal. Relevantly, biofilm-forming C. albicans cells exhibited resistance to all studied antifungals. So, new effective drugs against resistant C. albicans isolates causing denture-related stomatitis are urgently required.
\end{abstract}

Keywords: Denture; Stomatitis; Candida; Antifungal resistance; Virulence factors

\section{Introduction}

Despite the advances in dental care, edentulous cases remain a significant issue, especially among elderly individuals. According to the Brazilian Oral Health Survey, $45 \%$ of elderly persons need to use complete dentures (Soares et al., 2018). Denture-related stomatitis is considered the most common disease to afflict denture wearers and it has been shown to affect approximately $50 \%$ of this specific population (Figueiral et al., 2015). The long-term use of dentures, associated with poor oral and prosthesis hygiene, increases the risk of development of stomatitis, which is characterized as an inflammatory disorder of the palatal mucosa usually caused by the proliferation of Candida spp., mainly Candida albicans

\footnotetext{
(c) The Author(s), 2020. Published by Cambridge University Press. This is an Open Access article, distributed under the terms of the Creative Commons Attribution licence (http://creativecommons.org/licenses/by/4.0/), which permits unrestricted re-use, distribution, and reproduction in any medium, provided the original work is properly cited.
} 
(Thilakumara et al., 2017). The competence of C. albicans to colonize the mouth mucosa and, subsequently, to induce a successful infectious process is closely related to the production of several virulence factors, including surface adhesins, extracellular enzymes and biofilm formation (Mello et al., 2017; Schaller et al., 2005; Willaert, 2018), as well as the host immune status (Swidergall, 2019).

\section{Objectives}

In the present study, we have investigated the antifungal susceptibility profiles as well as the production of potential virulence attributes in oral isolates of Candida albicans recovered from denture-related stomatitis of elderly patients attended at the dentistry clinic of a Brazilian University (Universidade Vale do Rio Doce - UNIVALE, Minas Gerais State, Brazil).

\section{Methods}

\section{Study design and ethics}

The present study was approved by the ethics committee (CAAE-39005514.5.0000.5157) and conducted at the dentistry clinic of UNIVALE, including elderly individuals ( $>60$ years-old), denture wearers, functionally independent and non-institutionalized.

\section{Sample collection and Candida identification}

Denture-related stomatitis diagnosis was defined by clinicians and samples were collected directly from oral lesions using a sterile swab (O'Donnell et al., 2015). Yeasts were morphologically identified by CHROMagar Candida ${ }^{\circ}$ (HiMedia-Laboratories, India), phenotypically by VITEK ${ }^{\odot} 2$ (bioMérieux, France) and molecularly by sequencing the ITS1-5.8S-ITS2 gene. Candida albicans ATCC 10231 was used as reference strain.

\section{Virulence attributes}

Biofilm formation on polystyrene surface and production of extracellular enzymes (aspartic protease, caseinase, phospholipase, esterase, phytase and hemolysin) were evaluated as previously described (Ziccardi et al., 2015). Two biofilm parameters were analyzed: biomass (measured in methanol-fixed biofilm using crystal violet dye) and metabolic activity (measured in non-fixed biofilm by metabolization of 2,3-bis (2-methoxy-4-nitro-5-sulfophenyl)-5-[(phenylamino)carbonyl]-2H-tetrazolium hydroxidemetabolization). The enzymatic activity was expressed as $\mathrm{Pz}$ value, which was calculated by the ratio of the diameter of colony per the diameter of colony plus precipitation zone.

\section{Antifungal susceptibility}

Antifungal susceptibility of planktonic-growing yeasts was conducted following the standard microdilution method published by Clinical and Laboratory Standards Institute (documents M27-A3/M27-S3/ M27-S4). The effect of antifungals on biofilm-forming cells was determined by a microtiter-based assay (Ziccardi et al., 2015).

\section{Statistics}

All experiments were performed in triplicate, in three independent experimental sets, and, when appropriated, the results were expressed as mean \pm standard deviation. 


\section{Results}

Fifty-two patients fitted our inclusion criteria and 4 (7.7\%) of them presented denture-associated stomatitis, being selected to the next experiments. Demographic data, dental history and oral hygiene habits were summarized in Table 1.

Candida was isolated from the lesions of patients with denture-related stomatitis. Morphological (green colonies in CHROMagar Candida), biochemical (carbohydrate assimilation/metabolic enzymatic profiles evaluated by VITEK 2 presented probability of identity to $98 \%$ ) and genetic (ITS sequencing alignment scores revealed $100 \%$ identity with reference isolates deposited in GenBank) analyses identified the fungal isolates as C. albicans.

Phenotypic assays showed that all $C$. albicans isolates produced esterase, being classified as good producers as suggested by the $\mathrm{Pz}$ values, besides aspartic protease and hemolysin (weak producers). However, no fungal isolate with the ability to produce phospholipase and caseinase was detected (Table 2). Biofilm on a polystyrene surface was detected as judged by the measurement of two classical parameters: biomass and metabolic activity (viability) (Table 2).

Planktonic cells of all C. albicans isolates were susceptible to amphotericin B (a polyene antifungal) and caspofungin (an echinocandin antifungal), while the susceptibility pattern to azoles varied from susceptible to resistant depending on both isolate and antifungal (Table 3). Impressively, biofilmgrowing C. albicans cells exhibited a remarkable resistance profile to all tested antifungal agents (Table 3).

Table 1. Demographic and oral characteristics of studied patients.

\begin{tabular}{llllll}
\hline $\begin{array}{l}\text { Strain } \\
\text { codes }\end{array}$ & Age & Gender & $\begin{array}{l}\text { Prosthesis } \\
\text { characteristics }\end{array}$ & $\begin{array}{l}\text { Dental-prosthesis } \\
\text { hygiene }\end{array}$ & $\begin{array}{l}\text { Denture-associated stomatitis } \\
\text { characteristics }\end{array}$ \\
\hline JSC & 74 & Female & TMP, TMdP & Regular & Erythematous candidiasis (palate) \\
\hline MAC & 67 & Female & TMP, PMdP & Good & Erythematous candidiasis (palate) \\
\hline MJR & 66 & Female & TMP, PMdP & Regular & Erythematous candidiasis (palate) \\
\hline NRV & 83 & Female & TMP, TMdP & Good & Erythematous candidiasis (tongue) \\
\hline
\end{tabular}

${ }^{\mathrm{a}} \mathrm{TMP}$, total maxillary prosthesis; TMdP, total mandibular prosthesis; PMdP, partial mandibular prosthesis.

Table 2. Hydrolytic enzyme production and biofilm formation by oral isolates of Candida albicans recovered from denturerelated stomatitis.

\begin{tabular}{|c|c|c|c|c|c|c|}
\hline \multirow[b]{2}{*}{$\begin{array}{l}\text { Strain } \\
\text { codes }\end{array}$} & \multicolumn{4}{|c|}{ Enzymatic activity $(\mathrm{Pz})^{\mathrm{a}}$} & \multicolumn{2}{|c|}{ Biofilm (Absorbance) } \\
\hline & Hemolysin & Esterase & Aspatic Protease & $\begin{array}{c}\text { Phospholipase/ } \\
\text { caseinase }\end{array}$ & $\begin{array}{l}\text { Biomass } \\
\left(\mathrm{A}_{590}\right)\end{array}$ & Viability $\left(\mathrm{A}_{492}\right)$ \\
\hline JSC & $0.861 \pm 0.061(w)$ & $0.410 \pm 0.004(\mathrm{~g})$ & $0.800 \pm 0.070(w)$ & $1 \mid 1(n)$ & $0.263 \pm 0.059$ & $0.296 \pm 0.059$ \\
\hline MAC & $0.923 \pm 0.009(w)$ & $0.600 \pm 0.210(\mathrm{~g})$ & $0.696 \pm 0.005(\mathrm{~g})$ & $1 \mid 1(n)$ & $0.360 \pm 0.084$ & $0.220 \pm 0.023$ \\
\hline MJR & $0.930 \pm 0.003(w)$ & $0.477 \pm 0.109(\mathrm{~g})$ & $0.800 \pm 0.007(w)$ & $1 \mid 1(n)$ & $0.263 \pm 0.075$ & $0.135 \pm 0.018$ \\
\hline NRV & $0.890 \pm 0.046(w)$ & $0.474 \pm 0.011(\mathrm{~g})$ & $0.800 \pm 0.042(w)$ & $1 \mid 1(n)$ & $0.260 \pm 0.075$ & $0.204 \pm 0.031$ \\
\hline \multicolumn{7}{|l|}{ ATCC } \\
\hline 10231 & $0.843 \pm 0.044(w)$ & $0.446 \pm 0.075(\mathrm{~g})$ & $0.894 \pm 0.007(w)$ & $1 \mid 1(n)$ & $0.317 \pm 0.093$ & $0.265 \pm 0.026$ \\
\hline
\end{tabular}

${ }^{a}$ The enzymatic activities were measured by the formation of a clear halo around the colony and expressed as Pz value as previously proposed by Price et al. (1982). The Pz value was scored into four categories: Pz of 1.0 was evaluated as negative ( $\mathrm{n}$ ); high Pz between 0.999 and 0.700 represents weak enzymatic activity $(\mathrm{w})$; moderate $\mathrm{Pz}$ between 0.699 and 0.400 represents good enzymatic activity $(\mathrm{g})$; low $\mathrm{Pz}$ between 0.399 and 0.100 represents excellent enzymatic activity. The results were expressed as mean \pm standard deviation of three independent experimental sets. 
Table 3. Susceptibility profiles of both planktonic- and biofilm-forming cells of oral isolates of Candida albicans recovered from denture-related stomatitis to different classical antifungals.

\begin{tabular}{lllllll}
\hline & & \multicolumn{3}{c}{ MIC/bMIC $[\mu \mathrm{g} / \mathrm{ml}]^{\mathrm{a}}$} \\
\hline Strain codes & Amphotericin B & Caspofungin & Fluconazole & Itraconazole & Voriconazole \\
\hline JSC & $0.5(\mathrm{~S}) />8(\mathrm{R})$ & $0.06(\mathrm{~S}) / 1(\mathrm{R})$ & $>64(\mathrm{R}) />64(\mathrm{R})$ & $0.5(\mathrm{SDD}) />64(\mathrm{R})$ & $0.5(\mathrm{SDD}) />64(\mathrm{R})$ \\
\hline MAC & $0.25(\mathrm{~S}) />8(\mathrm{R})$ & $0.06(\mathrm{~S}) />8(\mathrm{R})$ & $>64(\mathrm{R}) />64(\mathrm{R})$ & $8(\mathrm{R}) />64(\mathrm{R})$ & $>16(\mathrm{R}) />64(\mathrm{R})$ \\
\hline MJR & $0.25(\mathrm{~S}) />8(\mathrm{R})$ & $0.06(\mathrm{~S}) / 4(\mathrm{R})$ & $2(\mathrm{~S}) />64(\mathrm{R})$ & $0.03(\mathrm{~S}) />64(\mathrm{R})$ & $0.06(\mathrm{~S}) />64(\mathrm{R})$ \\
\hline NRV & $0.25(\mathrm{~S}) />8(\mathrm{R})$ & $0.06(\mathrm{~S}) / 2(\mathrm{R})$ & $>64(\mathrm{R}) />64(\mathrm{R})$ & $0.06(\mathrm{~S}) />64(\mathrm{R})$ & $>16(\mathrm{R}) />64(\mathrm{R})$ \\
\hline ATCC 10231 & $0.5(\mathrm{~S}) />8(\mathrm{R})$ & $0.125(\mathrm{~S}) />8(\mathrm{R})$ & $4(\mathrm{SDD}) />64(\mathrm{R})$ & $0.5(\mathrm{SDD}) />64(\mathrm{R})$ & $0.5(\mathrm{SDD}) />64(\mathrm{R})$ \\
\hline
\end{tabular}

${ }^{\mathrm{a}} \mathrm{MIC}$, minimum inhibitory concentration for planktonic cells; bMIC, minimum inhibitory concentration for biofilm-forming cells; R, resistant; S, susceptible; SDD, susceptible-dose dependent.

\section{Discussion}

Denture-associated stomatitis is related to both exogenous and endogenous factors, which can lead to differences in prevalence and clinical manifestations' severity (Thilakumara et al., 2017). In this context, published works reported a broad range of stomatitis prevalence in middle aged or elderly, varying from 10 to $85 \%$, with females being affected slightly more commonly than males (Bianchi et al., 2016; Rivera et al., 2017). Our study revealed a low prevalence (7.7\%) of denture-related stomatitis and these selected patients were all female (mean age $70.5 \pm 7.9$ years-old). Our Dentistry sector has a small flow of patients attended at the University clinic. However, this small flow of patients has a positive impact in our studies permitting us to follow each patient more close. The socioeconomic conditions as well as the good oral hygiene are possible hypothesis to justify the small number of denture-associated stomatitis detected in our patients.

C. albicans was isolated from all stomatitis patients, being able to produce biofilm and hydrolytic enzymes, two well-known virulence attributes. Biofilm is a physical barrier that prevents the penetration of antimicrobials and host defenses (Mello et al., 2017). In a general way, hydrolytic enzymes are capable in destroying cell/tissue structures, including proteins and lipids, and humoral defense molecules, like antibodies, complement system proteins and antimicrobial peptides (Schaller et al., 2005).

\section{Conclusions}

In our clinical samples, oral isolates of $C$. albicans resistant to azoles, including fluconazole that is commonly used to treat denture-associated stomatitis, were detected. The isolation of $C$. albicans able to form biofilm is a veritable problem, because it is one of the main causes of antifungal treatment failure. Moreover, the secretion of hydrolytic enzymes able to destroy host tissues/cells can increase the local inflammatory response, aggravating the clinical manifestations and the disease progression. So, it is urgently necessary to consider new treatment options to combat infections caused by resistant isolates of C. albicans. In this context, new drugs with anti-C. albicans action and novel compounds able to block the expression of virulence factors should be discovered to improve the antifungal armamentarium to be used in clinical settings.

Acknowledgments. The authors would like to thank Denise Rocha de Souza, who is supported by FAPERJ scholarships, for her technical assistance.

Funding Information. This work was supported by grants from Fundação Carlos Chagas Filho de Amparo à Pesquisa do Estado do Rio de Janeiro (FAPERJ), Conselho Nacional de Desenvolvimento Científico e Tecnológico (CNPq) and Coordenação de Aperfeiçoamento de Pessoal de Nível Superior (CAPES - Financial code 001).

Disclosure statement. The authors declare that there is no conflict of interest. 
Author Contributions. LVNFS, ACMG, MHB, HMSC and ALSS conceived and designed the study. LVNFS, CDOM, ISC, JMP, LCRA, MFV, MBM, TSP, LOPS, ACMG performed the experiments. LVNFS, ACMG and ALSS compile the data. LVNFS, ACMG, MHB, HMSC and ALSS wrote the article. All authors have read and agree to the submitted version of the manuscript.

Data availability. The authors confirm that the data supporting the findings of this study are available within the article.

Ethics statement. The authors assert that all procedures contributing to this work comply with the ethical standards of the relevant national and institutional committees on human experimentation and with the Helsinki Declaration of 1975, as revised in 2008.

\section{References}

Bianchi, C. M., Bianchi, H. A., Tadano, T., Paula, C. R., Holffmann-Santos, H. D., Leite, J. R., \& Hahn, R. C. (2016). Factors related to oral candidiasis in elderly users and non-users of removable dental protheses. Revista do Instituto de Medicina Tropical de Sao Paulo, 58, 17.

Figueiral, M. H., Fonseca, P., Lopes, M. M., Pinto, E., Pereira-Leite, T., \& Sampaio-Maia, B. (2015). Effect of denture-related stomatitis fluconazole treatment on oral Candida albicans susceptibility profile and genotypic variability. The Open Dentistry Journal, 9, 46-51.

Mello, T. P., Ramos, L. S., Braga-Silva, L. A., Branquinha, M. H., \& Santos, A. L. S. (2017). Fungal biofilm - A real obstacle against an efficient therapy: Lessons from Candida. Current Topics in Medicinal Chemistry, 17, 1987-2004.

O'Donnell, L. E., Robertson, D., Nile, C. J., Cross, L. J., Riggio, M., Sherriff, A., Bradshaw, D., Lambert, M., Malcolm, J., Buijs, M. J., Zaura, E., Crielaard, W., Brandt, B. W., \& Ramage, G. (2015). The oral microbiome of denture wearers is influenced by levels of natural dentition. PLoS One, 10, e0137717.

Rivera, C., Droguett, D., \& Márquez, M. J. A. (2017). Oral mucosal lesions in a Chilean elderly population: A retrospective study with a systematic review from thirteen countries. Journal of Clinical and Experimental Dentistry, 9, $276-283$.

Price MF, Wilkinson ID \& Gentry LO (1982) Plate method for detection of phospholipase activity in Candida albicans. Sabouraudia 20: 7-14.

Schaller, M., Borelli, C., Korting, H. C., \& Hube, B. (2005). Hydrolytic enzymes as virulence factors of Candida albicans. Mycoses, 48, 365-377.

Soares, F. F., Freire, M. C. M., \& Reis, S. C. G. B. (2018). The 2010 Brazilian oral health survey (SBBrasil 2010 project): What do the coordinators propose for future surveys?. Interface (Botucatu), 22, 981-989.

Swidergall, M. (2019). Candida albicans at host barrier sites: Pattern recognition receptors and beyond. Pathogens, 8, 40.

Thilakumara, I. P., Jayatilake, J. A. M. S., Pallegama, R. W., \& Ellepola, A. N. B. (2017). Denture-induced stomatitis and associated factors in a group of patients attending a university dental hospital in Sri Lanka. Journal of Investigative and Clinical Dentistry, 8, e12211.

Willaert, R. G. (2018). Adhesins of yeasts: Protein structure and interactions. Fungi (Basel), 4, 119.

Ziccardi, M., Souza, L. O. P., Gandra, R. M., Galdino, A. C. M., Baptista, A. R. S., Nunes, A. P. F., Ribeiro, M. A., Branquinha, M. H., \& Santos, A. L. S. (2015). Candida parapsilosis (sensu lato) isolated from hospitals located in the Southeast of Brazil: Species distribution, antifungal susceptibility and virulence attributes. International Journal of Medical Microbiology, 305, 848-859.

Cite this article: de Sousa LVNF, de Oliveira Maia CD, Carvalho IS, Prata JM, Arcanjo LCR, de Figueiredo Vieira M, Martins MB, Pereira TS, Souza LOP, Galdino ACM, Branquinha MH, Canela HMS, Santos ALS (2020). Candida albicans isolated from denture-related stomatitis in elderly patients: Antifungal susceptibility and production of virulence attributes Experimental Results, 1, e43, 1-9. https://doi.org/10.1017/exp.2020.49 


\section{Peer Reviews}

\section{Reviewing editor: Dr. Alicja Dabrowska}

Cambridge University, Department of Physics, Cambridge, United Kingdom of Great Britain and Northern Ireland, CB2 1TN

This article has been accepted because it is deemed to be scientifically sound, has the correct controls, has appropriate methodology and is statistically valid, and met required revisions.

doi:10.1017/exp.2020.49.pr1

Review 1: Candida albicans isolated from denture-related stomatitis in elderly patients: antifungal susceptibility profiles and production of potential virulence attributes

Reviewer: Prof. Valentina Arsić Arsenijević ${ }^{1}$

${ }^{1}$ University of Belgrade Faculty of Medicine, Institute of Microbiology and Immunology, Beograd, Serbia, 11000

Date of review: 17 July 2020

(C) The Author(s), 2020. Published by Cambridge University Press This is an Open Access article, distributed under the terms of the Creative Commons Attribution licence (http://creativecommons.org/licenses/by/4.0/), which permits unrestricted re-use, distribution, and reproduction in any medium, provided the original work is properly cited.

Conflict of interest statement. no

Comments to the Author: Swab method is not appropriate as we showed in this manuscript "LaboratoryBased Investigation of Denture Sonication Method in Patients with Candida-Associated Denture Stomatitis". Please, stress the limitation of the study and add this manuscript as reference.

\section{Score Card}

Presentation

4.0

Is the article written in clear and proper English? (30\%)

Is the data presented in the most useful manner? (40\%)

Does the paper cite relevant and related articles appropriately? (30\%)

Context

Does the title suitably represent the article? (25\%)

Does the abstract correctly embody the content of the article? (25\%)

Does the introduction give appropriate context? (25\%)

Is the objective of the experiment clearly defined? (25\%) 
Analysis

Is the conclusion consistent with the results and discussion? (40\%)

Are the limitations of the experiment as well as the contributions of the experiment clearly outlined? (20\%) 


\section{Review 2: Candida albicans isolated from denture-related stomatitis in elderly patients: antifungal susceptibility profiles and production of potential virulence attributes}

Reviewer: Dr. Michael Nevels ${ }^{1}$

'University of St Andrews, Biomolecular Sciences Building, Fife, United Kingdom of Great Britain and Northern Ireland, KY16 9ST

Date of review: 18 August 2020

(C) The Author(s), 2020. Published by Cambridge University Press This is an Open Access article, distributed under the terms of the Creative Commons Attribution licence (http://creativecommons.org/licenses/by/4.0/), which permits unrestricted re-use, distribution, and reproduction in any medium, provided the original work is properly cited.

Conflict of interest statement. Reviewer declares none.

Comments to the Author: This is a small, overall well-presented study with clear tables. Before publication, the authors should address the following points:

1. Briefly discuss the limitations of this study, especially the small number of stomatitis patients under investigation.

2. Simplify the title. For example, “....and production of potential virulence attributes" may be shortended to "....and potential virulence attributes/factors" or " $\ldots$ and production of virulence attributes/factors".

3. Expand Statistics section (page 5). Are these standard deviations in Table 2?

4. Define "Pz values" in the main text (page 5).

5. Amend "all patients" (page 6) to "all stomatitis patients" for clarity.

6. Simplify long and complex sentences like those starting with "Candida was directly isolated..." (page 5) and "To worsen this scenario,..." (page 6).

7. Proof-read the entire text for minor language inconsistencies including small grammatical errors.

\section{Score Card}

Presentation

Is the article written in clear and proper English? (30\%)

Is the data presented in the most useful manner? (40\%)

Does the paper cite relevant and related articles appropriately? (30\%)

\section{Context}

Does the title suitably represent the article? (25\%)

Does the abstract correctly embody the content of the article? (25\%)

Does the introduction give appropriate context? (25\%)

Is the objective of the experiment clearly defined? (25\%) 
Are the limitations of the experiment as well as the contributions of the experiment clearly outlined? $(20 \%)$ 